\title{
Validity and Legal Conflicts
}

\section{Stephen Munzer*}

The doctrine that valid legal rules cannot conflict has not received the direct and detailed consideration it merits. Even those who have defended the doctrine have not laid entirely bare their disposition to embrace it. Some of the arguments presented in its defense reflect the belief that conflict between valid rules would amount to logical contradiction; others seem to assume that the notion of legal obligation associated with the concept of validity is conclusive and precludes the existence of two conflicting valid rules applicable to the same situation. However, more explicit investigation of the question whether two valid legal rules can conflict is in order. For it does not reduce to the often simple and tedious problem of whether a certain concept applies to a given item or situation. It rather goes to the root of our understanding of legal validity and of its relation to legal obligation.

My object in this article is to show the doctrine that valid rules cannot conflict to be false. I shall argue that neither the concept of validity itself nor any other factor excludes such conflict. The deployment of my argument first requires, however, an analysis of what it means for two rules to conflict.

\section{The Nature and Types of Legal Conflict}

Several problems relating to individuation, though of great interest and importance, are essentially irrelevant to the present discussion and will be put to one side. Legal philosophers have long been engaged in the attempt to show how the content of a legal system should be individuated, i.e., divided into smaller units of legal material, which they have variously called "commands," "rules," "norms," "laws," "principles," "policies," and so on. The first of the problems to be set aside is whether the elements of a legal system may include items between which conflict would uniformly be regarded as innocuous. Under at least one interpretation of The Concept of Law, H. L. A. Hart includes only duty-imposing and power-conferring rules in the inventory of a modern legal system, and most would find conflict

- B.A. 1966, University of Kansas; B.Phil. 1969, Oxford; J.D. 1972, Yale Law School. 
between such rules to be troubling. In contrast, Ronald Dworkin contends that a legal system also includes elements, which he calls "principles" and "policies," that plainly can "intersect" or conflict." I shall confine my discussion to conflicts between "legal rules." The second problem to be distinguished is the proper individuation of items between which the possibility of conflict is deemed a matter of concern. So, for example, Hans Kelsen divides the content of legal systems into "norms" which direct officials to impose sanctions upon the satisfaction of certain conditions, and no conflict among such norms is admitted to be possible. ${ }^{2}$ Joseph $\mathrm{Raz}$, on the other hand, categorizes a number of different types of "laws," between which conflict is possible but also (at least usually) resolvable within the system. ${ }^{3}$ Any theory of individuation that allows for conflicts which other portions of the system are competent to resolve must show such conflicts to be compatible with the concept of validity. In this essay, however, I shall focus on the more difficult and fundamental problem of whether conflicts can occur between "legal rules" that are not resolvable within the legal system. I would emphasize that I am not committing myself to any particular doctrine of individuation. The various sorts of conflict I shall identify can, if perhaps more ponderously, be expressed under other theories of individuation.

For the purposes of this article I shall distinguish between legal rules that impose duties and those that grant permissions. "Duty-imposing" rules subject someone to a legal duty or obligntion. A full statement of such a rule specifies some person or class of persons (the "norm-subject"), some act or type of act (the "norm-act"), and the circumstances in which the rule applies (the "conditions of application"), ${ }^{4}$ and indicates whether in those circumstances the norm-subject is to perform, or to forbear performing, the norm-act. "Permissiongranting" or "permissive" rules indicate that in certain circumstances the norm-subject is allowed to perform, or to abstain from performing, the norm-act. Permissive rules do not on this account include

1. The Model of Rules, 35 U. CuI. L. REv. 14 (1967), reprinted under the litle Is Law a System of Rules?, in Essiys in Legal Philosophy 25, 39 (R. Summers ed. 1968) [hereinafter cited as Dworkin, The Model of Rules, with page references to the reprinted article]. See also Dworkin, Comments on the Unity of Law Duclrine, in ETucs AND Socist. JUstick. 200, 202 (H. Kiefer \& M. Munitz eds. 1970) [hercinafter cited as Dworkin, Comments on the Unity of Law Doctrine]; Dworkin, Social Rules and Legal Theory, 81 YiLE L.J. 85j, 882-88 (1972).

2. See H. Kelsev, General Theory of LaIY and State (1945); H. Kelsen, Pure Tueori of LAw (M. Knight transl. 1967).

3. See J. Raz, The Concept of a Legar Srstear (1970); and, more recently, Raz, Legal Principles and the Limits of Law, 81 YALE L.J. 823 (1972).

4. This terminology is derived from G.H. von Wrigir, NORM AND .ICrion 70.92 (1963). 
"bare" permissions, i.e., those situations in which the law is silent and hence there is simply an absence of a legal duty. I make this exclusion because it is a mistake to speak of a rule conflicting with a bare permission.5 I am concerned here only with "explicit" permissions. These may be created in situations where the law states expressly that an act, though presently neither prohibited nor required, may be performed or that its non-performance is allowed; or where the law terminates an existing obligation; or (at least usually) where the law establishes certain formalities that must be complied with if certain consequences it wishes as a general matter to facilitate, or make room for, are to result. ${ }^{6}$ While these examples may not be exhaustive and do not in any case provide a rigorous account of the difference between bare and explicit permissions, they are sufficient to prepare us for the main question.

That question is: "What is it for two rules to conflict?" If we restrict attention to situations involving two rules, an answer to this question must deal with three different combination-types or cases. (i) Two duty-imposing rules may require and forbid the same action by the same person at the same time. For example, one rule may require all doctors to treat persons found injured on the roadway, while another rule may prohibit them from doing so. (ii) A rule may impose a duty on certain persons to act (not to act) at a certain time, while another rule may permit such persons not to act (to act) at that time. Thus one rule may prohibit all doctors from treating persons found injured on the roadway, while another may permit them to do so. (iii) A rule may allow certain persons to act at a certain time, and another may allow them not to act in that way at that time. For instance, a rule may allow doctors to treat persons found injured on the roadway, while another rule may permit them not to treat such persons.

An agreeably simple answer-and one that has enjoyed some favor in the literature - to the question posed would find conflict when and only when joint (simultaneous) conformity to two rules having

5. See note 13 infra.

6. It must be emphasized that the law is in this last situation doing a very great deal besides, as the various discussions of legal powers show. See, e.g., H.L.A. HART, Tilb CONCEPT OF LAw 27-41, 78-79, 238-39 (1961); J. RAz, supra note 3, at 162.66, 181.83; Hart, Bentham on Legal Powers, 81 YALE L.J. 799 (1972). I do not wish to attempt herc a proper analysis of those rare cases in which the law confers a power to perform an act it seems to forbid, e.g., where as in some legal systems it sometimes grants a thicf the power to make a valid transfer of stolen property even though he commits an offense in doing so.

7. See, e.g., Hart, Kelsen's Doctrine of the Unity of Law, in ETHICs AND Socint JusTaE 171, 183-85 (H. Kiefer \& M. Munitz eds. 1970) [hereinafter cited as Hart]. 
the same norm-subject is logically impossible. This theory of the nature of conflict seems to deal tolerably well with case (i). For each duty-imposing rule we may frame an indicative statement ("conformity statement")-e.g., "Doctor $\mathrm{X}$ treated injured person $\mathrm{Y}$ on the roadway" and "Doctor $X$ did not treat injured person $Y$ on the roadway." The duty-imposing rules in question would conflict because it is logically impossible that both conformity statements, on the assumption that the same persons and occasion are being referred to, could be true. ${ }^{8}$ Finding conflict to be present in cases of type (i) seems to accord with our ordinary intuitions as to when a conflict exists. But the joint conformity theory deals very awkwardly, if at all, with cases (ii) and (iii). If one "conforms" to a permissive rule by doing what it allows, ${ }^{9}$ joint conformity is in these cases logically impossible, and, if we adhere to the theory, we must say that a conflict exists. Now in case (ii) we might be willing to apply the word "conflict" if the normsubject acted on the permissive rule; for he would then have violated a duty-imposing rule. But if the norm-subject discharged his obligation under the duty-imposing rule, we would usually be reluctant to say that he was in a situation of "conflict" merely because he did not simultaneously act on the permissive rule. So far as cases of type (iii) are concerned, our inclination would be to say, at least as to the example introduced in the preceding paragraph, that the two permissive rules do not conflict at all. Yet the joint conformity theory would commit us to precisely the opposite conclusion. One could complicate the theory by stipulating that the joint conformity test simply does not apply to cases of type (iii) and that permissive rules cannot ever conflict. ${ }^{10}$ But this is merely an ad hoc restriction imposed to salvage the plausibility of the theory. And it prevents us from acknowledging the presence of conflict in certain more complex instances of type (iii)-a point to which I shall later return.

The source of all these difficulties with the joint conformity theory is that it neglects to distinguish separate questions and confusedly at-

8. It is essential to distinguish sharply the question whether two conformity state. ments are logically inconsistent from the question whether two conflieting rules are so. Conformity statements are assertions as to what is or has been the case, and accordingly their consistency or inconsistency is a matter of "indicative" logic. Rules. on the other hand, are concerned with what is obligatory or permitted, and their consistency or inconsistency is the province of "deontic" logic. See note 62 infra.

9. Since the word "conformity" is normally restricted to doing what a rule imposing an obligation requires, an extension of the term is involved in using it also to characterize acting on or availing oneself of a permission, i.e., doing what a permissive rule allows. This should occasion no difficulty so long as it is remembered that 1 am using the word in this special sense, because my arguments will not depend on the ordinary language characteristics of such words as "conformity" or "compliance."

10. This is the move made by Hart, supra note 7 , at $185 \mathrm{n.43}$ (198). 
tempts to respond to them all in terms of a single principle. The sentence "What is it for two rules to conflict?" has the form of a single question. Without attempting to sort out all the different queries it raises, I would suggest that at least two closely related but nonetheless distinguishable questions should be separated: (a) "What is it for two rules to conflict in themselves, i.e., apart from any given norm-subject's complying with or acting on them, or his failing to do so?" (b) "What is it for two rules to conflict on a particular occasion by virtue of an act or omission by a norm-subject?" This distinction sometimes figures, though perhaps not explicitly, in nontechnical discussions of the law or a person's legal position. At times, for instance, we focus on the language of two legislative enactments and attempt to decide whether there is some incompatibility between them. At other times, however, we ask whether on a particular occasion a person violated one rule when he satisfied an obligation or availed himself of a permission created by another rule.

How should these separate questions be answered? That two rules conflict in themselves does require that joint conformity to both is logically impossible. But it also requires, I believe, that on at least some particular occasion, by performing or omitting the norm-act, the rules might conflict. I include this second requirement because it would be idle and highly unusual, though perhaps not meaningless, to say that two rules conflict-even in themselves-when there cannot be at least one norm-subject put into some sort of quandary by the coexistence of the rules. Cases (i), (ii) and (iii) all plainly meet the first requirement. Cases (i) and (ii) also clearly satisfy the second. In case (i), the performance of one obligation by the norm-subject is ipso facto a failure to perform a competing obligation. In case (ii), conflict on a particular occasion will exist (at least) when the norm-subject violates the duty-imposing rule by acting on the permission. Whether situations in case (iii) can ever give rise to a conflict on a particular occasion is a closer question which can be dealt with only after a more thorough analysis of conflict on a particular occasion.

That two rules conflict on a particular occasion by virtue of an act or omission by a norm-subject presupposes that joint conformity to those rules is logically impossible. But it also requires that on that occasion the rules clash or collide. The notion of clash or collision is in this context metaphorical, but it suggests the idea of sharp disagreement or opposition implicit in the etymology of "conflict."11

11. The word is derived from the Latin verb confligere, meaning "to strike together, clash, conflict, contend, fight." 
The words "clash" and "collision"-which I shall use interchangeably -are meant to capture this idea of sharp disagreement or opposition and of the quandary in which norm-subjects are placed by rules requiring or allowing incompatible courses of behavior. To be somewhat more specific, two rules clash or collide if, and only if, any act or omission of the norm-act type figuring in the rules violates, or results in the violation of, a duty-imposing rule or some strong and intimately connected pressure or policy in favor of a permissive rule.

Consider the examples introduced earlier. Case (i) will present a conflict on every occasion involving a norm-subject for whom the conditions of application are satisfied. For any act or omission of the type in question, e.g., treating an injured person on the rondway, would violate one rule or the other. ${ }^{12}$ Case (ii) is more complicated. Now if the norm-subject avails himself of the permission, e.g., by treating an injured person on the roadway, there is surely a conflict on that occasion, since he thereby violates the duty-imposing rule. ${ }^{13}$ Normally, no conflict will exist on any occasion when the norm-subject discharges the obligation imposed by the duty-imposing rule and simply declines to act on the permissive rule. But the answer may be different if there is a strong pressure or policy, intimately related to the permission, for the norm-subject to avail himself of the permission. Suppose that we alter the example originally introduced for type (ii) combinations so that one rule prohibits doctors from treating patients found injured on the roadway and another permits such treatment. Suppose that neglecting to treat such persons is a hideous violation of professional ethics, accepted morality, and express public policy to reduce roadway deaths. Assume further that the permission to treat such persons is corroborated by the law in various ways, e.g., by depriving one treated of the right to sue for battery, by setting a

12. This holds, at any rate, so long as the rules are not logically defective in their formulation. In other words, the statement in the text should prove true unless the norm-subject is a null class, the norm-act is not in fact an act, the conditions of application can logically never be satisfied, or some logical inconsistency exists in the characterization of these elements. This qualification also applies to the other two types of conflict identified.

13. It should now be clear why permissive rules cannot in this context be understood to include bare as well as explicit permissions. Suppose that at one time a country had no law relating to alcoholic beverages, but later prohibitcd their manufacture and sale. If the initial bare permission is considered the product of a permissive rulc, that rule and the subsequent duty-imposing rule conflict in themsclies, and they conflict on a particular occasion whenever anyone acts on the permission by manufacturing or selling alcoholic beverages. But it would be grotesque to describe this situation as a conflict, and $I$ cannot imagine that anjone would do so. Even if one vere to resort to some reconciliative mechanism, such as lex posterior derogat priori, the distortion would not be eliminated. For no one would say that there existed some prior law (the bare permission) which needed to be repealed by the subsequent prohibition in order to resolve a conflict. 
lower standard of professional care for such treatment, or even by offering physicians some reward for saving injured persons. In this case, I think it is accurate to say that the rules "clash" or "collide" even when the norm-subject does not act on the permission. Certainly, on such an occasion the norm-subject is put in a quandary, created by general and strong principles of social responsibility, quite different from the mere bafflement he might feel if simultaneously forbidden and permitted to do an act that neither law nor society seeks to promote. ${ }^{14}$

Case (iii) raises still more complex issues. The suggestion that permissive rules can conflict at all may seem dubious. The doubt is indeed well-founded where the element of clash or collision can never be present and hence there can be no conflict on any particular occasion. For example, joint conformity to the rules "All passengers may board one hour prior to departure" and "All passengers may abstain from boarding one hour prior to departure" is logically impossible. ${ }^{15}$ But these rules can never clash. Any passenger may act on either of these permissions without difficulty and without violating any obligation. Since these rules can never conflict on a particulir occasion, it would be idle and counter-intuitive to suggest that they even conflict in themselves. Nevertheless, there are perhaps two restricted sets of cases that do involve conflict. The first, an analogy with certain type (ii) conflicts just discussed, consists of instances in which the norm-subject acts on one permission and thereby fails to act on a different permission which is backed by a strong, intimately related pressure or policy. The second set consists of cases in which both permissions are acted on and thereby produce a conflict of either of the first two types. Hence, a rule permitting a legislature or judge to lay down a rule requiring certain persons to file a United States income tax return and a second rule permitting them to lay down a rule requiring or permitting said persons not to file would be in

14. If I understand him correctly, Dworkin scems to allow that it may sometimes be realistic to describe two rules as conflicting if one forbids what another permits, though he plainly thinks it would be bizarre to do so in many cases. He does not, however, focus clearly and consistently on the difference between whether two rules conflict in them. selves and whether they do so on a particular occasion. Moreover, his examples are drawn chiefly from the conflict of laws; this introduces complexities as to jurisdiction and de. ciding which rule to apply that I have thought it better to avold. The relation of Dworkin's views to the account offered in the text is thus not entirely clear. See Dworkin, Comments on the Unity of Law Doctrine, supra note 1, at 203.05.

15. For convenience $I$ shall construe these sentences as stating two scparate permis. sive rules, rather than a single rule that passengers may board one hour prior to de. parture or not as they please. This construction may have the advantage of being more accurate in those cases where explicit permissions to do and to omit doing a certain act are granted at different times, or by different law-creating authorities, or both. 
conflict if the rules created were themselves in conflict or brought into conflict. ${ }^{16}$ In other words, taking advantage of both permissive rules by a legislature or judge would result in the violation by taxpayers of a duty-imposing rule or of some pressure or policy that favors acting on a permission. The two permissive rules would conflict in themselves because joint conformity to them is logically impossible and on at least some particular occasions they would conflict. Those occasions would be when the rules collide by virtue of the collision of rules they in turn create. Here a clash exists since the incompatibility latent in the two permissive rules has been triggered or brought to the surface. Joint conformity to these two permissive rules is, of course, no more possible than to the two passenger-boarding rules described earlier. A salient difference, however, exists between these two pairs of rules. The same passengers availing themselves of different rules at different times, or different passengers availing themselves of different rules at the same or different times, does not result in the creation of new rules. By contrast, new rules are created when, mutatis mutandis, the norm-subjects of the rules relating to laying down requirements as to tax returns take advantage of them in these ways. Indeed, if they did not take advantage of them in some such ways, no conflicting rules could be created in this case. Some justification for considering these cases as instances of conflict lies in the way we think about the law. If two duty-imposing rules or a dutyimposing and a permissive rule conflict, we seek an explanation in terms of the process which led to their existence. An explanation can at least sometimes be given by reference to rules which permitted the conflicting rules to be created. Although two permissive rules can plainly be analyzed as a source of conflicting rules, this does not preclude our regarding them also as a special type of conflict.

I should not like here to press further my sense that some sorts of permissive rules can conflict. The matter clearly requires further analysis. Quite beyond the issue of conflicts between permissive rules, a fully adequate theory of legal conflict must deal with many questions I have had to ignore. To what situations would speakers of English apply the term "Iegal conflict"? Would consideration of the cases and literature in the discipline known as the conflict of laws

16. The relatively simplified manner in which I have described this situation is adequate for present purposes, but it will often be important to distinguish between "permissions" and "authorizations," and to frame an example more carcfully in observance of the difference between legality/illegality on the one hand and validity/invalidity on the other. On the latter point, see Hart, Bentham on Legal Pourers, 81 Yale L.J. 799, 816 (1972). 
shed further light on the nature of legal conflict? Can an account of the sort offered here deal adequately with all varieties of conditional obligations and conditional permissions? Would it be useful to distinguish between "partial" and "total" legal conflicts? To the extent that the notion of impossibility is involved, should we make reference only to what is logically impossible? Or should we also include cases of "causal impossibility," e.g., where there are obligations to do A and not to do B, yet A causes B, or "financial impossibility," e.g., where there are obligations to do $A$ and to do $B$, but no one has sufficient funds to do both?

If I ignore these questions here it is not because I think them uninteresting or unimportant. So as not to leave the reader guessing at what I mean by "legal conflict," I have attempted to provide a substantial, though not complete, theory of the nature and types of legal conflict. The argument presented in the remainder of this article holds, however, for any reasonable explanation of legal conflict, and for simplicity's sake I shall just speak of legal conflict and not distinguish between conflicts in themselves and conflicts on a particular occasion.

\section{Legal Conflicts and the Concept of Validity}

Is the concept of legal validity such as to insure that conflicts between valid legal rules will never occur? Of course the term "legal validity" has had different meanings for different writers. I shall attempt to show that a concept of legal validity which does not preclude the possibility of conflict is to be preferred.

\section{A. Validity as Legal Strength or Adequacy}

A theory of validity, so far as analytical jurisprudence is concerned, should illuminate in a clear and coherent way the concept of validity actually found and used in the law. This does not mean that it must parrot what judges, lawyers, legal writers, and others say about the concept of validity. For they may not be wholly consistent ${ }^{17}$ or provide the full, rigorous elaboration of the concept that the legal theorist seeks. But it does mean that their use of this concept is of central importance. An account of validity should be accepted only if it illuminates the practical employment of the concept and assists our theoretical understanding of it and of related areas of legal thought.

17. In this connection, see note 38 infra. 
I have attempted elsewhere to provide a satisfactory theoretical analysis of the notion of validity used by lawyers and others. ${ }^{18}$ I suggested that when we say a rule is "valid" we mean that it is "legally strong or adequate," "good or sufficient in point of law." Apart from what might be called the meaning (in the strict sense of synonymy) of "valid" and "validity," the statement that something is legally valid entails that if applicable it may not legally be ignored or overthrown, i.e., it would be a violation of a legal duty or obligation to do so. For example, if a will is valid, a court may not ignore it and proceed as if the testator had died intestate, but rather must see that within certain limits his instructions are followed. A distinct but related point is that a rule or act in the law or legal instrument will be valid if, and only if, it satisfies criteria established by other rules of the system. Thus to be valid, a legal rule, for example, must ordinarily be issued or enacted by an authority which has the legal competence to do so, this authority must follow the required procedures for such issue or enactment, and the resulting rule must not conflict with more authoritative rules, e.g., those contained in a written constitution. This general account of legal validity is applicable at least to legal rules, acts in the law, and legal instruments.

Two aspects of this theory of legal validity merit further comment. On the one hand, validity is a formal notion: The law sets criteria that particular legal rules, acts in the law, and legal instruments must satisfy in order to be valid. On the other, validity is also a normative concept. The words "valid" and "validity," at least as often used by those subject to a legal system, function in part as terms of normative appraisal. If something is valid, it is seen to have certain normative consequences. On one level, these consequences apply to those who are immediately subject to or affected by, say, a valid legal rule. It is for this reason that lawyers and judges as well as legal theorists speak of valid rules of obligation as having "binding force" on those whose behavior they regulate. For a similar reason valid rules that confer powers are considered to have certain normative effects if the appropriate persons take advantage of them. On a second level, these normative consequences also apply to legal officials. Either as part of something implicit in valid rules themselves, or as the result of some general provision of the legal system, we consider that

18. See S. Munzer, Legat Validrty 37-42 (1972). Whether valid rules an conflict was not considered in my monograph, and further analysis of the nature of validity has been necessary to deal with this question. Only the present paragraph in the text represents a summary of my earlier investigations. 
legal officials must apply all and only valid rules in the appropriate circumstances. They have a legal duty not to ignore behavior that fails to conform to valid duty-imposing rules and not to fail to give effect to actions performed in accordance with valid power-conferring rules. Hence, employment of the concept of legal validity simultaneously looks backward to formal criteria a rule must meet to be valid and forward to the application of a given rule and its attendant normative consequences.

But what is the force of "legal duty" or "legal obligation" here? If a rule is valid and applicable in a certain situation, is this conclusive, i.e., does a judge or other legal official have an absolute obligation to apply it, which no other considerations can defeat? Or does he have only a prima facie obligation to apply the rule, an obligation that can be overridden in certain circumstances? It seems to me that he has only a prima facie obligation. Usually, of course, if a valid rule is applicable there is no further question as to whether a judge - must actually apply it. ${ }^{10}$ But what is usually so is not what is always or necessarily so. There seem to me several situations where we might say that this obligation can be overridden. One, as I shall argue more fully below, is where two valid rules conflict. For if a legal official has an absolute duty to apply two conflicting valid rules, then the system has in effect put him in a position where he must violate one duty or the other-and this seems intuitively unacceptable. A second case is where the appropriate criteria of validity are satisfied, but, though there is no conflict, considerations militate against applying the rule. If these considerations are extremely powerful, they may be sufficient to override the official's prima facie obligation to apply the rule. ${ }^{20}$

The idea that these situations should be analyzed in terms of prima facie, rather than absolute or conclusive, obligation may seem more congenial if we look at an analogous case in moral philosophy. To the extent that one may speak of moral rules and of validity in moral contexts, most would agree that there are valid moral rules dictating that we keep our promises and not tell lies. In some cases both rules

19. I am concerned here with the difference between whether a rulc is applicable or actually applied. For the different but in some respects analogous distinction between whether a rule is applicable and whether it should be applied, sec Note, Understanding the Model of Rules: Toward a Reconciliation of Dworkin and Positivism, 81 YALE L.J. 912, $917-21$ (1972).

20. This latter point cannot be argued further here. For recent papers offering analyses generally compatible, though not necessarily identical, with that tentatively suggested in the text, see, e.g., Kadish \& Kadish, On Iustified Rule Departures by Officials, 59 Calif. L. Rev. 905 (1971); Note, Understanding the Model of Rules: To. ward a Reconciliation of Dworkin and Positivism, 81 YALE L.J. 912, 917.21 (1972). 
may be applicable and will thus conflict. Suppose, for example, that I have promised a friend to tell the police that he is in San Francisco even though he is, as I am well aware, in Boston. I can keep my promise only by telling a lie and can tell the truth only by breaking my promise. Many philosophers would analyze this as a case of conflicting prima facie obligations, and whether one obligation or the other should be overridden will depend on such matters as the consequences of complying with one rule rather than the other.

Under the concept of legal validity described above, there is nothing to prevent valid legal rules from coming into conflict. A rule is "legally strong or adequate" or "sufficient in point of law" if it has satisfied the appropriate criteria of validity and no subsequent event, e.g., a legislative act, has terminated its validity. The observation that legal validity requires the satisfaction of criteria does not preclude conflict. For there is nothing in the bare notion of satisfying criteria that excludes the possibility that the set of criteria of validity possessed by a legal system should prove mutually incompatible in respect of the set of possible rules that might satisfy them. No doubt it is desirable that they should prove compatible, and no doubt in practice they normally do. But what is desirable or usually (or even invariably) the case is insufficient to establish that conflict between valid rules is logically impossible.

In concluding that the concept of validity does not show conflicting valid rules to be logically impossible, I am not appealing to a line of judicial decisions that has reached precisely this conclusion. But it is not merely for reasons of theoretical simplicity or elegance or convenience that $I$ take the concept of validity not to preclude legal conflict. For it seems to me that a proper understanding of some of the more general features of the notion of validity used by judges, lawyers, and others also compels us to reach this conclusion. And I shall shortly argue that any theory holding conflict between valid rules to be logically impossible must run afoul of certain prominent features of our ordinary notion of validity.

The conclusion that valid rules may conflict does not dictate what legal consequences will ensue. If there is such a conflict, it logically follows that the norm-subject cannot jointly conform to both and that a judge cannot simultaneously apply both in deciding a case. Whether after a decision in such a case both rules can survive as valid rules of the system depends, not or not merely on the logic of "validity," but on the characteristics of the adjudicative practice and judicial system in question. If an adjudicative practice does not have 
a doctrine of precedent, nothing logically prevents both rules from continuing to be valid, with their range of application unaltered. Even where stare decisis is a feature of an adjudicative practice, the consequences are far from clear. In the United States, for example, we find coexisting a dual system of state and federal courts. In each system there are courts which are subordinate, coordinate, or superordinate vis-à-vis other courts within that system; certain types of lawsuits may be brought in either state or federal court, though in some instances a suit may be "removed" from one to the other; complex rules exist as to when federal law must be applied in state courts and state law in federal courts; and, while the Supreme Court stands as the final arbiter, appeal to it is not always legally possible, and in most cases the Court may and generally does exercise its discretion not to review a decision of a lower court. If we take stare decisis to mean that a decision in one court must be followed in relevantly similar future cases by courts on which its decision is controlling, we see at once that in the United States the consequences of a decision actually to apply one of two conflicting valid rules is a rather complicated matter. A court's decision may leave both rules valid in other parts of the United States judicial system and indeed may coexist with a decision to precisely the opposite effect by some other court within that system. A decision not to apply an applicable and valid rule, then, does not have as many logical consequences as may be supposed, and its other consequences depend on whether the doctrine of precedent is accepted and on the nature and structure of the judicial system in question.

\section{B. Defects of a Conclusory Notion of Validity}

The previous section sets out my chief reasons for rejecting the view that the concept of validity itself excludes the possibility of legal conflict. But it is useful to consider in more detail the alternative that the notion of legal duty associated with the concept of validity is conclusive, that the legal official's obligation to apply a valid legal rule can never be overridden. This alternative does not inevitably lead to the conclusion that valid legal rules cannot conflict. One might say that in cases of conflict an official has an absolute, indefeasible duty to apply two incompatible rules, and so is in a situation where he can do nothing right. Though not logically inconsistent, this position is nevertheless implausible and unpalatable because we would not think of conflicts-even irreconcilable conflicts-in this way. If a conflict arose that the legal system were incompetent to resolve, we would 
usually feel that any official faced with a decision would somehow have it within his discretion to settle matters as best he could. For this reason I think that most who are willing to embrace the alternative being considered would, at least as to the overwhelming number of cases in which the system has not explicitly deprived the official of the discretion necessary to come to a decision, adopt a different position. They would say that this absolute concept of obligation leads to a conclusory notion of validity and hence that conflicting valid rules are logically impossible. On this view, a decision not to apply a rule that is applicable is a decision that it is invalid. As we shall see, this position seems to be that taken by Dworkin and possibly by Kelsen. ${ }^{21}$

I cannot "prove" that the conclusory notion of validity is "wrong." The concept of legal validity is perhaps not so sharp and clear as to make the conclusory notion patently silly. Further, to some degree a philosopher can be master of his words and stipulate that a term is to bear a certain meaning. Yet, though "validity" is not a term of art like "fee tail" or "adjusted gross income," it is by no means exclusively or even predominantly a theorist's concept. It is rather part of our ordinary legal currency. To be persuasive the conclusory notion must elucidate the general understanding of validity possessed by lawyers and others. But in at least three respects it fails to do so.

First, the conclusory notion separates from the ordinary concept of legal validity one of its most distinctive features. I refer here to the fact that something is valid if, and only if, it satisfies criteria set out elsewhere in the legal system. Judges, lawyers, legal writers, and others are often concerned with detailing the requirements that a legal rule, act in the law, or legal instrument must meet to be valid.22 This feature of the ordinary employment of validity cannot be part of the conclusory notion of validity; for, since there is no assurance that the criteria relating to what we normally call validity must prove mutually compatible in respect of the rules meeting them, conflicting rules might satisfy them. It would therefore be logically inconsistent to say both (i) that validity turns on the satisfaction of criteria and (ii) that validity is conclusory in the sense explained. And it is a mistake to jettison (i) rather than (ii), because (i) together with an account of valid rules in terms of a prima facie legal obligation on legal officials, preserves and elucidates the way in which the participants in a legal system think of validity, while (ii) does not.

21. See pp. 1156-68 infra.

22. See, e.g., the general criteria set for a valid warrant in REstATEstent (SEcoND) of ToRTs $\S 123(1965)$. 
Second, the conclusory notion of validity would construe legal "strength" or "adequacy" or "sufficiency" in a dubious way. If validity is both conclusory and elucidatory in these terms, they must also be given a conclusory, absolutist sense. Thus if a rule is valid, its strength, adequacy, or sufficiency would preclude its application ever being defeated or overridden. It does not seem to me that many lawyers would be altogether happy with this reading. For example, many would say that the notion of strength clearly admits of degree in some fashion. If something is strong, that does not prevent something else from overriding it. Roughly the same point holds, though less obviously, in the case of adequacy and sufficiency. Adequacy is generally used in legal contexts to mean fully equal to legal requirements or occasions. ${ }^{23}$ This accords with its more general employment to cover whatever is commensurate or equal to what is required or fitting. ${ }^{24}$ But this hardly prevents something else from being adequate as well. The word "sufficiency," when it does not bear simply the same meaning as "adequacy," 25 is often used in a prima facie way that allows that something which is sufficient may be surpassed or overridden. ${ }^{20}$ The conclusory notion of validity, unlike the concept of legal validity I have argued for, thus disables us from entertaining interpretations in line with the common usage of these terms.

In reply, it might be urged that at least sometimes the courts have used "validity" in a conclusory sense. I concede that judges have occasionally used "validity" in a way that is arguably conclusory. A closer consideration of their opinions, however, reveals that they were intending, not to oppose the concept of validity defended here, but to distinguish validity from some other concept. Although a review of every relevant case is hardly possible, an example will help to make my point clearer. The language of Sharpleigh $v$. Surdam ${ }^{27}-$ a decision often cited by courts wrestling with the meaning of "validity"-is stronger than any $I$ have encountered. The issue there was whether

23. See, e.g., Commonwealth $e x$ rel. Attorney General v. Mathues, 210 Pa. 372,425 , 59 A. 961, 981 (1904) ("adequate" means "fully equal to requirements or occasions"). A few courts have apparently used the word "adequate" less stringently. See Eaton v. Patterson, 2 Stew. \& P. 9, 19 (Ala. 1832); Sutherland v. Sutherland, 187 Kan. 599, 605, 358 P.2d 776, 781 (1961); Greenwood v. Greenwood, 96 Kan. 591, 595, 152 P. 657, 650 (1915).

24. See Oxford Encish Dictionary (1933), s.v. "adequate." The word is derived from the Latin verb adaequare, meaning "to make or become level or equal."

25. See, e.g., Pcople v. Kiser, 112 Cal. App. 2d 903, 905, 245 P.2d 1125, 1126 (1952) ("adequate" means "fully sufficient").

26. See, e.g., Parker v. Overman, 59 U.S. (18 How.) 137, 141.42 (1855) ("sufficient" in Arkansas statute is a synonym for "prima facie", not "conclusive"): State v. Newton, 33 Ark. 276, 284 (1878) ("sufficient" means "prima facie"). See also Note, Causation and Liability in Private Actions for Proxy Violations, 80 YALE L.J. 107, 186 (1970).

27. 21 F. Cas. 1173 (No. 12,711) (C.C.W.D. Tenn. 1876). 
a tax sale was valid or not. The applicable statute provided that only proof of certain facts could invalidate the sale, and the question was whether "irregularities"-i.e., a variety of technical defects in the sale procedure not mentioned in the statute-would render the sale invalid. In answering this question in the negative, the court said that "validity" means "legal sufficiency and complete obligation"; anything "valid" is "in a plenary sense lawful and indefeasible."28 The context in which these remarks were made, however, discloses that the court was concerned to distinguish the concept of validity from that of regularity. "Regularity" is a technical term used by lawyers in connection with the rather formal aspects of a practice or proceeding. A tax sale, for instance, would be considered "regular" if the sale were properly advertised, the officer in charge sold the property to the highest bidder, and so on. "Validity," on the other hand, concerns more than these formal requirements. A tax sale might be "regular" in every way, yet "invalid" if, for example, the officer purporting to sell the property did not have the legal power to do so because his commission had expired. It was this distinction between validity and regularity that exercised the court in Sharpleigh.29 The court did not face the philosophical question of whether there can be two conflicting rules applicable to a given situation, each of which satisfies the relevant criteria of validity.

Third, the conclusory notion of validity would compel us to conflate considerations of a quite disparate character in making assessments under the rubric of validity. Determining whether a rule is valid would, on the conclusory notion, involve deciding both (i) whether the rule satisfies the criteria relating to rules of its type and (ii) whether certain rather special considerations defeat the application of an otherwise applicable and valid rule. Only (i) is properly a matter of validity. Hence, to run these typically disparate decisions together under the heading of assessments of validity is to obscure their distinct character. Now I would grant that, in some cases, deciding whether a rule satisfies the appropriate criteria of validity may be nearly as difficult as deciding whether special considerations defeat its application. For example, the validity of laws in the United States relating to religion or to the exercise of free speech is often dependent on constitutional provisions having a long and tortured history of judicial interpretation. Determining whether laws of this type are valid may call for all the powers of judgment possessed by

28. Id. at 1178, 1179.

29. The court in fact well illustrates the distinction. Id. at 1178-79. 
the wisest court. But this does not justify conflating (i) and (ii). For even if the issues in some extremely difficult cases may go to validity, they do not do so in all or even most cases. This is a simple point, but nonetheless fundamental, as it relates importantly to the way we think of validity. Suppose, for example, that we have concluded that a penal statute satisfies the applicable criteria of validity and that a certain person falls within its range of application. Suppose further, however, that we feel that powerful considerations militate against applying the statute to him. If so, we are not asking if the statute is valid. We are rather considering whether it should, on balance, be applied to this person. The case may prove most intractable, but it would be a distortion to portray this as anxious deliberation over the validity of the statute. As a general matter, what is fundamentally at issue in many difficult cases is something other than validity. If that is correct, it would count against the conclusory notion of validity, which would require us to reach just the opposite conclusion.

Proponents of the conclusory notion of validity might, I suppose, argue that they never wished to deny that two valid conflicting rules could be applicable to a situation, only that a judge could ever actually apply two such rules simultaneously in the same case. But if this is all the conclusory notion of validity means, its interest evap. orates. Of course a judge could never actually apply two conflicting rules to the same case. Just as joint conformity to two conflicting rules is a logical impossibility, so is their joint application by a legal official. But this has nothing to do with validity. The same would hold if only one, or if neither, of the rules were valid. The reason that two conflicting valid rules cannot both be actually applied turns solely on the fact that they conflict. But to say that this is all that is at issue is to ignore the root question-whether two conflicting valid legal rules can both be applicable to the same situation.

\section{Dworkin and Kelsen on Validity}

\section{Dworkin: Conflict and Obligation}

It is useful to inquire, in some more directly textual fashion, whether on some defensible account of validity conflicts might be precluded. The account offered in passing by Dworkin in his interesting and valuable essay, The Model of Rules, which emerges in the context of his distinction between rules and principles, does 
not allow conflicting but valid legal rules. "Rules are applicable in an all-or-nothing fashion. If the facts a rule stipulates are given, then either the rule is valid, in which case the answer it supplies must be accepted, or it is not, in which case it contributes nothing to the decision." 30 Principles, on the other hand, have a dimension of "weight" and may conflict. "But we cannot say that one rule is more important than another within the system of rules, so that when two rules conflict one supersedes the other by virtue of its greater weight. If two rules conflict, one of them cannot be a valid rule." 31 By contrast, it is said to be "odd to speak of a principle as being valid at all, perhaps because validity is an all-or-nothing concept, appropriate for rules, but inconsistent with a principle's dimension of weight."32

It is difficult, I think, to ascertain exactly what is being said here. ${ }^{33}$ These passages seem to be directed at showing, or at least stating accurately, that our ordinary concept of validity excludes the possibility of conflicting yet valid rules. But if so the discussion is vitiated by two central mistakes. In the first place, these passages partially conflate, or misconceive the relation between, the quite distinct concepts of the validity and the applicability of standards. Consider, for instance, the rule that all male United States citizens must register with the Selective Service System after reaching their eighteenth birthday. ${ }^{34}$ This rule is valid if, and only if, it satisfies certain criteria set out elsewhere in the system; it must, for example, be promulgated by the Director of Selective Service in a way determined by and within the limits of the Universal Military Training Act. The rule in ques-

30. Dworkin, The Model of Rules, supra note 1, at 37.

31. $I d$. at 40 .

32. Id. at 55 .

33. The difficulty is compounded by Dworkin's most recent discussion of conflicts in Social Rules and Legal Theory, 81 YALE L.J. 855, 882.88 (1972), whose relation to the views put forward in his earlier essay is not entirely clear. On the one hand, he appears to be partly engaged in a defense of his earlier views on legal conflicts; certainly at no point does he explicitly retract them. On the other, some of his language suggests that his position is now less firm: "I did not deny, in my original article, that conflicts in rules might exist. I said that in our legal system such conflicts vould be oc. casions of emergency, occasions requiring a decision that would alter the set of standards in some dramatic way." Id. at $883-84$. At least part of this I can aceept. I agree that legal conflicts are emergencies, though in my opinion whether a decision would alter the standards in question depends on whether the legal system accepts the doctrine of precedent, and even if so to what extent those standards would be aliered in the systcm as a whole turns on the structure of the judicial system in question. It may be that in this passage Dworkin is chiefly concerned to allow that moral rules may conflict, and that even if legal rules do conflict the conflict is considered resolvable. In any case, it should be observed that in this most recent essay he focuses, not on whether there are irreconcilable conflicts between valid Iegal rules, but on whether two rules should be understood to be in conflict when one plainly has the force of an exception to the other, see id. at 884-87. For this reason, I shall here concentrate on the philosophical merits of the position outlined in The Model of Rules.

34. 32 C.F.R. § 1611.1(a) (1972). 
tion is applicable to a given case, however, if, and only if, the situation or circumstances referred to by the rule obtain, i.e., if, and only if, the person before the court was at the time of the alleged violation a male United States citizen who had attained the age of eighteen. A rule may be valid without being applicable; even in a close case, the decision that a rule is not applicable in a given situation does not entail that it is invalid. ${ }^{35} \mathrm{It}$ is thus plain that validity and applicability are two distinct concepts. The first of the passages quoted earlier $^{36}$ nonetheless seems in some measure to run them together. While Dworkin may in most respects attend to the distinction between validity and applicability, he does not do so insofar as he fails to observe with sufficient precision the difference between validity and defeasibility of application. The assertion that rules are "applicable in an all-or-nothing fashion" should be distinguished both from the statement that validity is an "all-or-nothing concept" and from the consequences of the applicability of a rule. That assertion might mean that applicability does not admit of degree, in which case nothing is said about the possibility of conflict between valid rules. On the other hand, it might mean that if a rule is applicable it must be applied. But if so, no support is offered for it, though the idea that rules cannot have weight seems to be invoked without argument.

Secondly, Dworkin's account interpreted in this way also misapprehends the relation between validity and weight in that it takes them to be mutually inapplicable concepts. Whether any given standard is valid depends on whether it satisfies certain criteria set out elsewhere in the legal system. So long as it is possible to separate in any way what is law from what is not, we may distinguish between valid and invalid standards. By contrast, whether any given standard has weight turns on whether, if that standard comes into conflict with another, ${ }^{37}$ the former's importance or centrality, and also the consequences of applying it or not, are relevant in deciding which standard to employ. Validity and weight are thus distinct concepts, though this does not in itself mean that one could never apply both concepts to the same item. It is said that "validity is an all-or-nothing

35. Of course, courts sometimes decide the applicability of a rule partly according to considerations of validity. Thus the applicability of a law may be construed narrowly so as not to render it of dubious constitutionality. An example of this may perhaps be found in Kent v. Dulles, 357 U.S. 116 (1958).

36. See p. 1157 supra.

37. This clause is not a petitio principii, for I am not here asserting that rulcs conflict, only that for any standards which do conflict we determine whether they have weight by seeing how they behave in such instances. If such factors as the centrality of a standard then come into play, it has "weight." 
concept, appropriate for rules, but inconsistent with a principle's dimension of weight." But this is a non sequitur. The concept of validity, it may be conceded, does not admit of degree. ${ }^{38}$ But it hardly follows that everything of which the word "valid" may be predicated cannot have different degrees of importance. ${ }^{39}$ It therefore does not follow either that rules cannot have weight or that anything in the concept of validity precludes its application to principles as well as rules. Consequently, nothing in the concept of validity has been shown to eliminate the possibility of conflicting yet valid rules.

The above criticisms hold against what seems to me one plausible interpretation of these passages. Yet, as Dworkin has pointed out to me in conversation, it is not exactly in this way that he wishes to be understood. The passages quoted are not attempting to prove that conflict between valid rules is impossible. They are concerned only

38. This statement may need several minor qualifications. First, the concept of validity does not preclude that some considerations may override the application of an other. wise applicable valid rule in certain circumstances. See pp. $1150-52$ supra. Second, writers sometimes, though perhaps misleadingly, use the expression "relative validity" to cover the situation in which one rule repeals or derogates, in whole or in part, the validity of another rule with which it conflicts. For an example of this use, sce TuE FEDERALIST No. 78, at 507 (Modern Library ed. E. Earle intro. 1937) (1. Hamilton). Neither of these qualifications, of course, is inconsistent with the idea that validity does not itself admit of degree.

But if validity does not admit of degree, it may be wondered whether there is some confusion in explaining it in terms of legal "strength" or "adequac)" or "sufficiency." The concepts of strength and probably adequacy, though perhaps not that of sufficienc); do in ordinary contexts admit of degree. Certainly it is commonplace to say that something is "stronger," and probably also that it is "more adequate," than another. Of course some arguments could be presented in defense of the law here. One would be that such degree as may pertain to the concepts of legal strength or adequacy is simply a reflection of the two points mentioned in the preceding paragraph. A subtler, and perhaps more plausible, argument begins from the thought that legal validity and legal strength or adequacy are not extensionally equivalent concepts. That is, while everything valid is legally strong or adequate, not everything legally strong or adequate is valid. What this argument invokes is the limited force the law at times bestows on rules or acts in the law or legal instruments that are voidable or cren void. A prominent example here would be the requirement that an injunction issuing from a court having jurisdiction be obeyed, even if invalid, until dissolved or reversed on appeal by a higher court. See, e.g., Walker v. City of Birmingham, 388 U.S. 307 (1967); United States v. United Mine Workers, 330 U.S. 258 (1947); Howat v. Kansas, 258 U.S. 181 (1929). The point of this example is that even though the injunction does not satisly the criteria of validity set by the system, it nonetheless possesses legal strength or adequacy in the sense that it must be obeyed until dissolved or reversed. The argument concludes by saying that everything valid possesses legal strength or adequacy to the same degree, but that there is a lower degree, or perhaps several lower degrees, of strength or adequacy which may be possessed by things that are not valid. While I would not contend that there is nothing in these two arguments, I am not confident that they free the language of some courts entirely of confusion. On occasion a judge may citc a dictionary definition without fully reflecting on the ways in which that definition may be misleading in a legal context. See, e.g., State v. Bd. of County Comm'rs of LeFlore County, 177 0.12. 470, 477, 60 P.2d 788 , 795 (1936). In any case, the present article and my monograph should be understood to embrace the elucidation of legal validity in terms of legal strength or adequacy only to the extent that that explanation is purged of any lingering confusion as to the admission of degree.

39. This applies to importance generally, not mercly to what Dworkin calls "functional importance." See Dworkin, The Model of Rules, supra note 1, at 39. 
to list a variety of differences between validity and weight, rules and principles, as Dworkin conceives them. That validity is an "all-ornothing concept" does not, or does not merely, mean that it fails to admit of degree; the idea is that it settles a question of legal duty. The remarks about validity and weight are intended to point to a functional similarity between the two concepts: Validity is to rules as weight is to principles. That is, validity is a concept we apply only to rules, and if a rule is valid it "dictate[s] [a] result, come what may," ${ }^{\prime} 0$ i.e., settles a question of legal duty. Weight is a concept we apply only to principles, and the amount of influence a principle has is proportional to its weight. ${ }^{41}$ It is perhaps true that Dworkin's position thus elucidated incorporates some features of the interpretation arrived at earlier simply by textual exegesis. The salient feature of this new interpretation or position, however, is that it seems to rest more explicitly on the assumption that the notions of legal obligation and legal validity jointly operate to preclude the existence of conflicting valid rules.

A full investigation of all the questions raised by this position cannot be attempted here, and I shall restrict myself to two points concerning validity. First, the passages from The Model of Rules, so interpreted, will readily be seen to embrace the conclusory notion of validity we considered at length above and rejected for reasons that do not need to be rehearsed.42 Second, Dworkin's particular theory is open to an additional objection. I have contented myself above with the observation that Dworkin does not prove that the concept of validity is logically inapplicable to principles. ${ }^{43}$ I shall now suggest, and in some measure attempt to show, that the opposite is true -viz. that our ordinary concept of validity is applicable to principles. That concept is applicable both to items, such as legal rules, that may have application in more than one set of circumstances, and to items, like acts in the law or legal instruments, that are tied to a

40. Id. at 49 .

41. Dworkin usually says that a principle cannot dictate a result; for example, "it states a reason that argues in one direction, but does not necessitate a particular decision." Id. at 38. But in one passage he writes that "a set of principles can dictate a result," though this does not mean that they can do so "come what may"-only rules can do that. Id. at 49 (emphasis in original). I shall not here inquire whether the putative distinction between "dictating a result" and "dictating a result, come what inay" is altogether clear and coherent.

42. See pp. $1152-56$ supra.

43. See p. 1159 supra. Dworkin's language sometimes suggests that it would only be a linguistic irregularity to refer to the validity of a principle ("[i]t scems odd to speak of a principle as being valid at all ..."), but at others it invokes the idea that the concept of validity is logically inapplicable to principles ("validity is ... inconsistent with a principle's dimension of weight"). Dworkin, The Model of Rules, supra note 1 , at 55 (emphasis added). I am here concerned only with the latter position. 
unique situation. Of items of the former type we say that they are, or are not, "members" of a legal system, though we rarely if ever make such an assertion in regard to items of the latter type. This fact may be stated more rigorously in this way: An item of the first type is a "member" of a legal system if, and only if, it satisfies the criteria of validity in that system. The point of asserting that such an item is valid is sometimes that it belongs to the legal system referred to. The point of the corresponding denial is sometimes that it does not belong to that system and perhaps not to any legal system. Now legal principles, if they exist at all, are items of the first type; like legal rules, they have potential application to different situations. For this reason we sometimes are concerned to say and to establish that a given principle is or is not a member of a particular legal system. And in those circumstances we would also say and try to establish that it is or is not valid. If so, our ordinary concept of validity is, pace Dworkin, indeed applicable to principles. ${ }^{44}$ The conclusory notion of validity therefore diverges from it once more and so again fails to elucidate our usual employment of the concept.

The conclusion that the concept of validity is applicable to legal principles might be attacked on the ground that it is incompatible with the way "valid" is often used in legal contexts. Many courts have said that if something is "valid" then it cannot legally be "ignored" or "overthrown"; yet it belongs to the very nature of a principle that it can be "ignored" or "overthrown." Again, insofar as validity is tied to obligation, it must be noted that while a principle may have great weight it cannot dispositively impose an obligation. This attack fails, I believe, because it does not pay sufficient attention to the way in which the courts use such terms. To my knowledge, assertions to the effect that something valid cannot legally be "ignored" or "overthrown" occur in judicial opinions only when courts are concerned with legal rules or with items such as judicial orders which can be given some plausible paraphrase in terms of legal rules. To "ignore" or "overthrow" a legal rule or judicial order, in the sense of declining to apply it, would in most situations in which it is applicable be to deprive it of its vitality. This is not so at all in the case of legal principles. Declining to apply a principle does not

44. One possible line of reply to this argument is to say that while our usual concept of validity is applicable to our ordinary understanding of principles and to some theoretical accounts of them, it is not applicable to Dworhinian principles. This reply does not seem to me very promising, as it only pushes the difficultics off onto a (resultingly) queer notion of principles without rescuing the conclusory notion of validity generally. I shall therefore not consider it here. 
spell its demise, for by definition the application of a principle may be defeated when it has less weight than a competing principle. In regard to the relation between validity and obligation, we must be careful to distinguish between (i) the obligation (if any) imposed on private persons and (ii) the obligation imposed on a legal official by a principle. As to the former, I would not of course claim that a principle imposes an obligation in Dworkin's sense of "dictating a result." A power-conferring or permissive principle imposes no ob. ligation at all; a principle of obligation imposes an obligation only to the extent that it is not overridden by competing principles. So far as the latter is concerned, however, a legal official does have an obligation to give a principle its appropriate weight. By this route we can see how the notion of validity is applicable to principles. A principle, if valid, may not be "ignored" or "overthrown" in the sense that a court can consistently fail to give it appropriate weight. Should such a failure consistently occur, the principle would indeed ultimately lose its validity. On the other hand, a valid and applicable legal rule, unlike a valid legal principle, would in most legal systems generally lose its vitality immediately if a court declined to apply it. This difference does not mean that the concept of validity is inapplicable to principles. It merely underscores in a special context the difference between rules and principles.

\section{Kelsen: Conflict and Logical Consistency}

I turn now to a second position, taken on some occasions by Kelsen, according to which valid norms may not conflict. Kelsen does not always subscribe to this view. Some passages in his writings construe validity not to preclude conflict; 45 and in several fairly recent articles he has stated, without much elaboration, that legal norms of the same system may conflict. ${ }^{40} \mathrm{But}$ at other times he has taken the

45. See, e.g., Pure Theory of LAw 18 (M. Knight transl. 1967): "The validity of a norm according to which a certain behavior ought to be ... does not exclude the pos. sibility of the validity of a norm according to which the opposite behavior ought to be." This passage is not, however, wholly free of textual difficulty. The paragraph in which the words quoted appear concludes in the German with a sentence that scriously qualifies, if it does not repudiate, the former: "Man kann die einc oder die andere Norm (aber nicht die beide zugleich) als gültig ansehen." REINE RECHTSLEHRE 18 (2d cd. 1960). (My translation: "One can regard one norm or the other (but not both at the same time) as valid.") This sentence was omitted by the translator, though it was duly rendered in the French translation (also approved by Kelsen), THEORIE PURE Du DKOIT 25 (C. Eisenmann transl. 1962), as follows: "On peut considérer comme valable soit l'unc soit l'autre norme; il est par contre impossible de les considerer comme valables et l'unc et l'autre à la fois."

46. See Kelsen, Die Grundlage der Naturrechtslehre, 13 OEsterReIcilsche ZeItschintT FUER OefFentliches Recht 1, 2-4 (1963); Kelsen, Derogation, in Essays IN JURISPRUdence iN HoNor of Roscoe Pound 339, 351 (R. Newman ed. 1962). 
opposite position, and it is with it alone that I shall be concerned here. Thus, Kelsen writes that a "system of norms can only be valid if the validity of all other systems of norms with the same sphere of validity has been excluded." 47 Similarly, in discussing the relation between law and morals, Kelsen says that "an individual who regards the law as a system of valid norms has to disregard morals as such a system .... [N]o viewpoint exists from which both morals and law may simultaneously be regarded as valid normative orders. No one can serve two masters." 48

How are these remarks to be understood? It might be said that Kelsen is pointing to a problem about obligation: that two valid norms cannot impose duties that are both incompatible and indefeasible. Dworkin, for example, has suggested that Kelsen's "concern is with the dynamics of legal reasoning . . . . Kelsen's view is that one person cannot regard both norms as valid in the sense of deciding the issue of what he ought to do on some occasion." 40 Beyond the fact that much of what Dworkin ascribes to Kelsen, e.g., concern with the dynamics of legal reasoning, seems more akin to Dworkin's thought than Kelsen's, this interpretation is ambiguous and does not in any case settle the issue. On the one hand, if Dworkin is construing Kelsen to say that since guidance cannot be taken from each of two conflicting norms, only one can be valid, Kelsen is saddled with the conclusory notion of validity that we have earlier considered and rejected. For that connection would hold only if the application of valid norms necessarily cannot be overridden. On the other, if Dworkin is reading Kelsen to say that since only one of two conflicting norms can be valid, guidance cannot be taken from both, Kelsen is consigned to begging the question. In either case, the position ascribed to Kelsen is rife with confusion. It is true that if

47. H. Kelsen, General Theory of Law and State 410 (1945).

48. H. KELSEN, PURE TheORY of LAW 329 (1967). It is perhaps not absolutely clear that, even in his books, Kelsen denies the possibility of conflicting valid norms within the same legal system. For example, the passage from which a sentence was just quoted from General Theory of Law and State at text accompanying note 47 supra is centrally concerned with putative conflict between law and morals. While the sentence I have reproduced is certainly broad enough to cover (and so deny the possibility of) conflict of valid norms within a legal system, it could certainly be argued that read in context it should not be so construed. The same argument could be made in connection with the sentence just quoted from Pure Theory of Law. But cf. id. at 74; GENERAL THEORY OF LAw AND STATE, supra note 47 , at 375 . See also note 45 supra.

49. Dworkin, Comments on the Unity of Law Doctrine, supra note I, at 201. Dworkin is not very clear as to whether this second position is a conceptual onc. Though he once refers to it as a "notion of validity," $i d$. at 201, he also describes it as an "analysis of validity," id., and earlier remarks that the word "validity" is being used "with different implications," $i d$. at 200. In the interest of simplicity I shall construe Kelsen as being concerned with a concept of validity or the meaning of "validity," as $I$ think that my criticisms can easily be recast to cover variant ways of stating this position. 
two norms conflict a person cannot simultaneously conform to both of them. So, in one sense at least, ${ }^{50}$ it is correct to say that a person cannot take guidance from both norms "in the sense of deciding the issue of what he ought to do on some occasion." But it is a confusion to think that this has anything to do with validity. As argued above, guidance cannot in this respect be taken from both norms simply because the norms conflict, not because only one can be valid."11 Thus, even if Dworkin's interpretation of Kelsen is correct, it is hardly a satisfactory theory of why the concept of validity should exclude conflict between valid legal norms.

I would suggest that Kelsen be read in quite a different way. He should be understood as saying that conflicting norms are logically inconsistent and that the concept of validity is such as to exclude the possibility of conflicting norms that are valid. Several points support this interpretation. First, some passages in Kelsen's General Theory of Law and State ${ }^{52}$ and Pure Theory of Law ${ }^{53}$ assimilate conflicts of norms to logical contradictions. Second, when Kelsen later abandoned the idea that valid norms cannot conflict, he apparently did so on the ground that " $a$ conflict between norms is not a logical contradiction and cannot even be compared to a logical contradiction." Third, Hart has advanced a plausible interpretation of Kelsen, more specific in certain respects than that put forward here, which also rests on a point about logical consistency. Hart writes that "Kelsen's claim that there can only be one system of valid laws resembles Kant's claim that there is only one space .... I have the impression that underlying Kelsen's theory of law there is the assumption that there is a single 'normative space' which must be describable by a consistent set of rules in a descriptive sense." 55 The reference here is to Kant's idea that "we can represent to ourselves only one space; and if we speak of diverse spaces, we mean thereby only parts of one and the same unique space." "sc Although I am not aware of anything that explicitly confirms or falsifies Hart's suggested interpretation, it seems to

\footnotetext{
50. This is true if taking "guidance" from a norm means obeying it. But it is perhaps not true if to take "guidance" from a norm is to consider not only what the norm re. quires but also the importance of a norm, the consequences of following it or not, and whether any norms requiring an incompatible course of behavior also apply. This latter construction leads us to the question whether rules can have weight.

51. See p. 1156 supra.

52. See, e.g., at 374-75.

53. See, e.g., at 74 .

54. Kelsen, Derogation, in Essays in Jurisprudence in Honor of Roscoe Pound 339, 351 (R. Newman ed. 1962).

55. Hart, supra note 7, at 182 n.32 (197-98) (emphasis in original).

56. I. Kant, Critique of Pure Reason A 25/B 39 (N. Kemp Smith transl. 1929).
} 
me consonant with what Kelsen says and with the Kantian overtones in Kelsen's work generally.

But two conflicting rules or norms need not be considered logically inconsistent. Hence, nothing in the concept of validity precludes such conflicts.57 It is, of course, true that on many accounts of the word "ought" and in many systems of deontic logic, the rules in a descriptive sense corresponding to Kelsen's "A ought to be" and "A ought not to be" will be logically inconsistent. We can infer a contradiction if we assume (i) that "ought" implies "can" and (ii) that "A ought to be" and "A ought not to be" jointly entail "A ought to be and ought not to be." Using (ii), we can derive "A ought to be and ought not to be." And, since A cannot both be and not be, we may employ (i) contrapositively to infer "it is not the case that $A$ ought to be and ought not to be." A logical inconsistency would also be present in many systems of deontic logic that are modeled on alethic modal logics. ${ }^{58}$ So, for instance, an alethic modal logic containing the axiom schema " $\square \mathrm{A} \supset \mathrm{A}$ " or some equivalent typically leads to a deontic system containing the axiom schema " $\square$ A $\supset$ $\square \sim A$ " or some equivalent. An ordinary language interpretation of the latter formula would be "it is not the case both that $A$ ought to be and that A ought not to be." Thus interpreted, this formula clearly denies that the statements that $A$ ought to be and that $A$ ought not to be can logically both be true. 50

57. In formulating the logical issues involved I have been greatly helped by Lemmon, Deontic Logic and the Logic of Imperatites, 8 Lorique eT ANALrSE 39 (No. 29) (196j) [hereinafter cited as Lemmon, Deontic Logic]; Williams, Consistency and Realism, Arust. Soc. Supp. Vot. XX at 1 (1966); Williams, Ethical Consistency, Arist. Soc. Surr. Vot. $\mathrm{XXXIX}$ at 103 (1965). Other essays of interest in this connection include Lemmon, Moral Dilemmas, 71 PhiL. Rev. 139 (1962); Lemmon, Is There Only One Correct System of Modal Logic?, Arist. Soc. Surp. Vol. XXXill at 23 (1959); Prior, The Paradoxes of Derived Obligation, 63 MIND 64 (1954). The fact that others may dispute their views does not affect the extremely guarded use I make of their ideas.

There are two responses to Kelsen's position that I shall not pursue here. One is that even if conflicting rules are logically inconsistent, nothing in the concept of validity, or any other factor, see note 64 infra, precludes that they should cxist in a legal systcm. The other response applies to Hart's interpretation of Kelsen: it is that conflicting rules are not inconsistent if they belong to unrelated normative spaces. $C f$. Quinton, Spaces and Times, 37 Phil. 130 (1962).

58. Alethic modal logic deals with statements of necessity and possibility. Deontic logic concerns statements of obligation and permission. In what follows, " $\square$ " is the symbol for necessity in alethic modal logic and for obligation in deontic logic; " 0 " is an abbreviation for " $\sim \sim$ "; the letter " $A$ " in an axiom schema is a metalogical variable rang. ing over well-formed formulae, though to simplity matters I shall later treat it as also ranging directly over statements or sentences; " ". " $\$ "$, and " $"$ " are the signs for truth-functional negation, conjunction, and material implication respectively. An clementary set of formation rules, axiom schemata, and rules of inference, together with some appropriate warnings and qualifications concerning the interpretation of symbols, may be found in Lemmon, Deonlic Logic, supra note 57, at $39-51$.

59. This formula is also a denial that the statements that $A$ ought to be and that not-A is permitted can logically both be true, and correspondingly its elimination in Lemmon's system allows that " $(\square A \& \& \sim A)$ " may under some circumstances be provable. 
Nevertheless, a deontic logic which allows for conflicting obligations has been suggested by $\mathrm{E}$. J. Lemmon..$^{60}$ In crude outline, this system eliminates " $\square \mathrm{A} \supset \sim \square \sim \mathrm{A}$ " as an axiom schema and so permits that under some circumstances " $\square$ A \& $\square \sim A$ )" will be provable, i.e., that in some cases $A$ and its opposite will both be obligatory. Lemmon recognizes that this requires abandonment of the principle that "ought" always implies "can," and accordingly he collects what seem to me plausible counter-examples to that principle.01 But I would not pretend that the situation is clearer than it is. Doubt rightly exists as to the ordinary language interpretation of the symbols used in deontic logic, as to the extent that any interpretation captures the character of and logical relations within actual codes of human behavior, and as to the acceptability of certain consequences of Lemmon's system. It should be plain, however, that some systems of deontic logic can arguably allow for conflicting obligations, and that whether such conflicts exist in law, morals, or elsewhere must be settled by investigation of particular codes or normative systems. Hence, deontic logic does not rule out the possibility of legal conflicts. ${ }^{02}$

It may be objected that a deontic logic which permits conflicting obligations is of no practical interest. After all, certain systems of indicative logic allow that under some conditions " $(\mathrm{P} \& \sim \mathrm{P})$ " may be provable; yet, in everyday life, we feel that simultaneously to assert the existence and nonexistence of an empirical fact amounts to logical contradiction. This objection is unsuccessful. The root issue is not whether a given system of indicative or deontic logic permits inconsistent propositions or conflicting obligations respectively, but whether any such logic can with plausibility be urged to apply respectively to human communication or codes of human behavior. Let it be granted that some indicative systems allow proof of "(P \& P)." But it does not follow that there are any plausible cases of inconsistent assertion. While concededly there are cases where people involve themselves in logical inconsistencies of which they are

60. Lemmon, Deontic Logic, supra note 57, at 43-51.

61. Id. at 47-48.

62. It is now possible to clarify the relationship between the logical consistency of conformity statements and that of rules. See note 8 supra. If we adopt the vicw that some sort of alethic modal logic should be made the model of deontic logic and include " $\mathrm{A} \supset \sim \square \sim \mathrm{A}$ " or an equivalent as an axiom schema, then in any case where the conformity statements corresponding to two duty-imposing rules or to a duty.imposing rule and a permission-granting rule cannot logically both be true, the rules will also be logically inconsistent. However, even where the conformity statements corresponding to two permissive rules cannot logically both be true, these rules will not be logically inconsistent, since in no system of deontic logic is " $(\Delta A \& \diamond \sim A)$ " logically incon. sistent. If, on the other hand, we adopt a Lemmon-style system of dcontic logic, in none of these cases will the rules themselves be logically inconsistent. 
unaware, they do not consciously do so in statements of the bald form "(P \& P)." To take a well-worn example, if in reply to the question "Is it raining?" someone says "Well, it is and it isn't," we do not take him to be asserting both that it is raining and that it is not raining. Rather, we interpret him as indicating a borderline case, e.g., that it is sleeting or drizzling. If he insists that it is both mining and not raining, we would earnestly try to convince him that he is wrong, and, failing that, say that he did not know the meaning of his words, was schizophrenic, or otherwise incapable of appreciating that he was contradicting himself. The same is not true with respect to statements about rules or norms. Contemporary logicians and moral philosophers of some repute have argued, in discussions dealing with ordinary moral language and thought, that there may be conflicting moral obligations and that the conflict may survive our having made one choice or the other on a particular occasion. It is equally arguable that conflicts can exist within a legal system. A deontic logic allowing for conflicting obligations can thus be urged with more than superficial plausibility to apply to actual codes of human behavior.

But to this way of dealing with the above objection someone might make the following rejoinder. If a person is in fact subject to conflicting obligations, he should be able to state both that it is, and that it is not, the case that he has a duty to do A. What is this but a proposition of the form " $(\mathrm{P} \& \sim \mathrm{P})$ "? That being so, would we not interpret his statement, as we did (mutatis mutandis) in the case where it was said to be both raining and not raining, so as to dissolve the appearance of conflicting obligation?

This rejoinder is vitiated by two mistakes. First, it may be doubted whether a statement of conflicting obligations should be rendered by the indicative formula " $(\mathrm{P} \& \sim \mathrm{P})$ " rather than the deontic formula "( $\square$ A \& $\square$ A)." ${ }^{33}$ In either case, it would beg the question, and is in fact erroneous, to assume that in all systems of indicative and deontic logic respectively these formulae are self-contradictory. Second, the rejoinder fatally ignores the context in which a statement of conflicting duties is made. It is perhaps true that, as a general matter, if a person said that he was under obligations to do and not to do an act, we would interpret what he said so as to render the duties compatible. This is because we suppose that by and large normative sys-

63. Strictly speaking, Kelsen's example "A ought to be" and " $A$ ought not to be" presents, if anything, logical contraries representable by the dcontic formula "(口 A \& $\square \sim$ A)." Contradictories are presented, if at all, only by "A ought to be" and "it is not the case that $A$ ought to be" representable in deontic logic by the formula "( $\square A$ $\& \sim \square$ A)." This technical point has for simplicity's sake been clided in the text. 
tems impose mutually compatible obligations. But we would not always seek such an interpretation. Should he be able to explain in a convincing way that the rules of the system in question really did oblige him both to do and not to do the act, we would concede that there really were conflicting obligations.

Whether there actually are or can be conflicting obligations thus requires further argument. But it begs the question to define "validity"-e.g., through axioms of deontic logic which make conflicting rules logically inconsistent-so as to exclude the possibility of legal conflict. Whether conflicting valid norms or rules can or do exist should be settled by the consideration of well-constructed examples or by reference to the rules of actual legal systems.

\section{Conflicting Valid Rules: An Example}

Thus far I have argued that there is nothing in the concept of validity to exclude the possibility of conflicting valid legal rules. Yet it does not follow that no other factor, e.g., the nature of systems of civil or criminal procedure, or the concept of a legal system itself, may preclude that possibility. ${ }^{64}$ Rather than attempt any compendium of the factors that might render conflicts between valid legal rules impossible, I shall offer an example that shows them to be possible. Such an example is indeed more difficult to construct than might be thought. But it is nevertheless possible, and the attempt to construct it leads to a number of interesting points concerning the nature of law.

It might be suggested that an example of irresolvable conflict can be produced with great ease. ${ }^{65}$ Imagine a country with a mature legal system in which there are two antagonistic religious sects, each a minority of the population. On a spot held sacred by sect $A$, there is a statue of the A's prophet and founder. Sect A persuades the religiously indifferent population to join them in influencing the nitional assembly to enact a penal statute that requires everyone to tip his hat when passing the prophet's effigy. The statute is, however, an abomination to sect $B$, and they persuade the middle group to support a bill prohibiting idolatry, construed as tipping one's hat to

64. Thus it might be argued that while the concept of validity imports no requircment of logical consistency, some other factor does and that conflicting valid rules arc logically inconsistent. Garcia Maynez, Some Considerations on the Problem of Anli. nomies in the Law, 49 ARCHIV FUER RECHTS- UNd SozIAll'HLLosorHIE 1, 4, 7 (196\$), sccins to adopt this view. But as we have earlier shown there to be no necessity to regard con. flicting valid rules as logically inconsistent, the above argument must fail.

65. The example initially produced in the text is an adaptation of one suggested by Alf Ross in Directives AND NoRMS 172-73 (1968). 
the prophet. The A's rally with a rider declaring that the former statute is to remain in force, and the sect $B$ bill, as amended, is then duly passed. The country now has two legal rules, one requiring and the other forbidding people to raise their hats when passing the prophet's statue. Neither of these two legal rules seems to be invalid; officials and ordinary citizens alike treat them as the law of the land. Nor is the law unworkable. Policemen usually avert their eyes, and prosecutors rarely seek indictments. Cases that do come to trial raise no special problems for the courts. If an accused has kept his hat on while passing the statue, a judge will punish him under the former law; if he has tipped his hat, he is punished under the latter one. In practice, people usually avoid the site of the statue, and if they must go near it they simply do not wear a hat.

Yet the briefest consideration of this example reveals a variety of difficulties which prevents us from seeing it tout court as a case of irresolvable conflict. First, is it obvious that both statutes are valid? It is not clear either what the applicable criteria of validity are or why the statutes meet them. Second, is it plain that the statutes are, in practice, incompatible? Because people generally avoid the statue or omit wearing a hat, it might seem that the total effect, if not the meaning, of the two statutes is simply to impose an obligation to stay away from the site or to leave one's hat at home-an obligation it is possible to satisfy. Third, what is to be said of the curious legislative history of the sect B bill? It is often, though not invariably, said that if two partially or wholly inconsistent statutes are passed at different times, then the later statute "repeals by implication" the earlier to the extent of the repugnancy.00 On the other hand, the rider supported by the A's that "the former statute is to remain in force" might well be interpreted as reaffirming the vitality of the earlier statute in such a way that it constitutes an exception to the sect $B$ bill. Fourth, under what rules of procedure are trials under either statute conducted? Although in the Anglo-American system the jury must determine the facts of the case, the judge must instruct them as to the applicable law. In this example, two conflicting rules are said to apply, but we are not told how the judge is to frame his instructions to the jury. It is far from clear that he is not legally entitled to avoid the difficulty by mentioning only one of the statutes.

66. See, e.g., Posadas v. National City Bank, 296 U.S. 497. 503 (1930); Red Rock v. Henry, 106 U.S. 596, 601-02 (1882); King v. Corncll, 106 U.S. 395, 396 (1882); Henderson's Tobacco, 78 U.S. (II Wall.) 652, 657 (1870); United States v. Tynen, 78 U.S. (1I Wall.) $88,92-93(1870)$. 
Conceivably, there might be a rule empowering him to dismiss prosecutions whenever conflicting rules are applicable to the facts alleged in the indictment. In sum, while I would not pretend that these four considerations exhaust the difficulties one might find with this example, they do indicate that in many legal systems there would be ample opportunity to reconcile or in some other way deal with the rules in question. The example does not, then, present a suitable case of irresolvable conflict.

A satisfactory illustration of conflicting but valid legal rules may be produced by modifying and expanding the example just discussed in such a way that the reconciliative devices often available in sys. tems of adjudication are ruled out. This may be achieved by making such alterations and adding such details as the following. The legal system contains rules requiring its citizens to wear hats and to make monthly visits within twenty feet of the statue. The sect $A$ statute reads: "Any person passing within twenty feet of the statue of the prophet must tip his hat." The sect $\mathrm{B}$ bill was then enacted with no rider and provides: "Any person passing within twenty feet of the statue of the prophet must not tip his hat." The expressions "the statue" and "the prophet" are used in the two statutes to refer respectively to the same objects, and a number of people while wearing hats do pass within twenty feet of the prophet's image. Violation of either of these statutes is a strict liability offense, and the penalty prescribed for each is ten days in jail, with guilt or innocence to be decided by the judge without a jury. To be valid, a statute must be introduced by a member of the national assembly, passed by a majority of that body, and signed by the premier of the country. The two statutes satisfy these criteria, and there are no other applicable criteria of validity in the system. Other relevant rules of the system include: a provision that the doctrine of repeal by implication is abolished and that statutes which are apparently or actually in conflict must be read together by the judge in deciding what is to be the law of the case; a canon of construction to the effect that only the wording of a statute is to be considered in deciding what it means and, in particular, that no court is entitled to look to legislative history in interpreting a statute; and sections of the criminal code which require a policeman witnessing a violation of any law to report it to the prosecutor, require the prosecutor to indict and bring to trial any person so accused, permit any defendant or his counsel to raise the point that two rules of the system are apparently or actually in conflict, and prohibit the judge from declining to 
take jurisdiction, render judgment, or impose sentence in cases of apparent or actual conflict.

This, it seems to me, does present a case of irreconcilable conflict. The rule that all persons passing within twenty feet of the statue must tip their hats, and the rule prohibiting them from doing so, are both valid, since they satisfy the applicable criteria of validity of the system. Yet these rules ${ }^{07}$ also conflict, since joint conformity to two such duty-imposing rules is logically impossible. Further, this conflict is not resolvable by appeal to rules or principles of the system. Suppose that $\mathrm{X}$ passed within twenty feet of the statue wearing a hat, and was observed by a policeman to keep it firmly on his head. The policeman duly reported this as a violation of the sect $A$ statute and $\mathrm{X}$ was brought to trial. The principles of statutory construction of the system prevent the judge from saying that no conflict exists, and he is forbidden to decline jurisdiction. Rather, he has a legal duty to determine what law governs the case and to render judgment, though ex hypothesi nothing in the system dictates what he must decide. What can he do? $\mathrm{He}$ has two principal choices: either he finds $\mathrm{X}$ guilty under the first law and sentences him to ten days in jail, or he finds him not guilty under the second and allows him to go free. There are a few less plausible choices, some of which might be permitted under a given adjudicative practice. He could, for example, treat the conflicting rules as self-cancelling and adjudge the defendant not guilty on that basis; he could, as it were, split the difference and sentence $X$ to five days in jail; he could refuse to apply either law and invent a third rule; and so on. In any event, he creates new law at least in deciding the case; if the system accepts the doctrine of precedent, his decision will be binding in similar future cases before courts on which his decision is controlling.

This example may be greeted with some suspicion, for it perhaps pushes very nearly to the limit what our intuitions regarding the nature of a legal system will allow. By considering a number of objections to the example, however, I shall try to show that it does not exceed that limit.

First, one might claim that this situation could never exist in a legal system. One might, for example, argue that the law could not regulate human behavior if it admitted of conflicting rules because citizens could not use such rules in ordering their behavior. Now it is true that the law could not perform this task if, as a general malter,

67. Although the example in the text may evince conflicts between several pairs of rules, I shall for simplicity's sake comment on just this one. 
it imposed conflicting obligations on those subject to it. Doubtless nothing but chaos would result. It does not, however, follow that in exceptional cases the rules of a stable and workable system could not conflict. A related argument is that judges would never explicitly avow that they must go beyond the law for a solution. But this is irrelevant. We are concerned with what judges do, not with what they say; with what actually forms the basis of a decision, not with what is employed in an opinion as a rationalization.

Second, one might object that these two rules were never both valid. The argument is that a rule is valid or invalid only when a court has pronounced upon it. Prior to such a pronouncement, we simply cannot say whether the rule is valid or not. In the example offered, if $\mathrm{X}$ is judged guilty, the sect $\mathrm{A}$ law is valid and the sect $\mathrm{B}$ law invalid; if $\mathrm{X}$ is acquitted, the situation is reversed. In either event, the law held to be invalid was, prior to the court's decision, not merely voidable but rather void, i.e., invalid ab initio. Consequently, there was no time at which the rule not applied was valid, and hence there were not really two conflicting yet valid rules.

This objection, however, misunderstands the role of criteria of validity and the use participants in a legal system make of them. Such criteria enable us to identify laws as valid or invalid by virtue of certain features or characteristics which they possess or lack. We normally do not have to wait for a court decision; we usually know that a rule will be valid if it satisfies certain conditions. ${ }^{08}$ Of course there are close cases in which opinions as to the validity of a rule not yet upheld by the courts are expressed very tentatively. But our usual employment of the concept of validity and of criteria of validity is such that we do not hesitate to say that a given rule is valid or invalid (as the case may be). Thus it would be a distortion to suggest that the sect A law and the sect B law, when both manifestly satisfied the applicable criteria of validity, existed in a sort of legal limbo. Though this seems to me sufficient to meet the objection, it is worth noting that the invocation of the idea of invalidity $a b$ initio in this

68. Cf. H.L.A. HART, THE Concert of LAw 229 (1961) (emphasis in original):

In the simpler form of society we must wait and see whether a rule gets accepted as a rule or not; in a system with a basic rule of recognition we can say beforc a rule is actually made, that it will be valid if it conforms to the requirements of the rule of recognition.

It seems to me that this holds in any system which contains criteria of validity. I do not, however, accept the idea that there must in every legal system be a rulc of recognition or some other type of single ultimate rule for deciding questions of validity. See p. 1174 \& note 71 infra. 
context is also far from satisfactory. ${ }^{\text {g9 }}$ It is doubtful that the objection observes the distinction between what is null or void, i.e., invalid $a b$ initio, and what is merely voidable as judges, lawyers, and others purport to draw it. For example, it has been argued that in English law an act is void if it can be attacked either directly or collaterally, and voidable if it can be attacked only directly. ${ }^{\circ 0}$ If so, and if in our example $X$ had been acquitted under the sect $B$ law, it is plain that the prosecution could not have attacked the judgment collaterally. Even if X had been convicted under the sect $\mathrm{A}$ law, it is far from clear that he could have made a collateral attack on the judgment. So those laws would seem at most to be voidable, not invalid $a b$ initio.

A third, and for our purposes final, objection questions whether conflicting valid rules are not resolvable within the system after all. Since a judge or other legal official cannot jointly apply two conflicting rules, it would seem that he must somehow make a choice between them. This objection also fails; for, while it rightly calls attention to a choice that the legal official must make, it wrongly concludes that this choice or resolution is necessarily made on the basis of material within the legal system. First, the resolution may be effected on the basis of no criteria, rules, or principles whatever. To say that choosing to apply one rule results from whim or caprice does not mean that the conflict is in any relevant sense resolved within the system. Second, even if the official is entitled to and does rely on certain criteria, rules, or principles, the objection is still not correct. It may be true that some legal systems contain reconciliative measures of the sort in question. My point is only that some do not, and hence that irresolvable conflicts between valid rules may occur in some legal systems. This point is supported by the facts (a) that some systems may preclude appeal to any outside means of resolving conflict; (b) that in others the criteria, rules, or principles to which appeal is allowable may not invariably be sufficient to resolve conflict; (c) that even if they were sufficient, it would not follow that those criteria, rules, or principles were part of the law and hence that the reconciliation was actually achieved within the system; and (d) that there is no guarantee that the criteria, rules, or principles to which appeal may be had are not themselves ever in irreconcilable conflict.

69. This is partly a matter of giving any suitable explanation of what it is for something to be null or void $a b$ initio. See, e.g., H. KELSEN, GENERAL TuEORY of LAW AND STATE 160-61 (1945).

70. See A. Rubinstein, Jurisdiction and Illegality: A Study in Public Lay pasim (1965). 


\section{Conclusion}

Save for one brief point, I cannot here explore the ramifications of the fact that valid legal rules can conflict. That one point is that my thesis implies the law to be in one respect not necessarily the neat and formal structure many legal philosophers have claimed. The view that legal systems are inescapably tidy and formal is, of course, a complex one, and perhaps no legal philosopher has ever accepted it in its entirety. One aspect of that view, for instance, may be found in theories which hold that every legal system contains a single ultimate rule that welds otherwise unrelated material into a unified legal order and serves as a touchstone for the validity of all other laws of the system. However, even if some test exists for separating what is law from what is not, it must, as I have argued elsewhere, on any acceptable theory of individuation consist of a plurality of rules. ${ }^{71}$ Another feature of the view that the law is tidy and formal is discredited if valid legal rules can conflict. The mistake lies in the assumption that, for some logical or quasi-logical reason, compatibility must obtain in the prohibitions and permissions that the law erects. The source of this error is the failure to appreciate that law is the result of human behavior, and in particular of the human acts of will and decision from which its standards spring. Human behavior, as we know all too sadly, does not always conform to what is rational. From pressures swaying legal officials in opposite directions, or out of human obtuseness or forgetfulness or perversity, laws may generate commands or permissions applicable to a given situation that cannot be simultaneously followed or acted upon. The human will is not so rational or the concept of legal validity so constituted as to prevent conflicting valid legal rules from coming into existence, nor is logic in any position to provide such assurance.

71. See S. Munzer, Legal Validtry 44.69 (1972). 